\title{
Genetic and Environmental Etiology of the Relationship Between Childhood Hyperactivity/ Inattention and Conduct Problems in a South Korean Twin Sample
}

\author{
Yoon-Mi Hur \\ Department of Education, Mokpo National University, Jeonnam, South Korea
}

\begin{abstract}
Recently, there has been increased research into the etiology of the comorbidity between hyperactivity/inattention problems (HIP) and conduct problems (CP). However, the nature of the etiology of the comorbidity has remained unclear. Mothers of 507 pairs of twins, comprised of 221 monozygotic (MZ) and 286 dizygotic (DZ) twin pairs aged from 6 to 13 years (mean $=9.6$ years; $S D=2.0$ years), completed the HIP and the CP scale of the Strengths and Difficulties Questionnaire (SDQ) via a telephone interview. The phenotypic correlation between HIP and CP was $0.43(p<.01)$. MZ and DZ twin correlations were, respectively, 0.48 (95\% Cl: $0.37-0.58)$ and 0.06 (95\% Cl: $-0.06-0.19)$ for HIP and $0.38(95 \% \mathrm{Cl}: 0.26-0.49)$ and 0.35 (95\% Cl: $0.25-0.45)$ for CP. The bivariate model-fitting results revealed additive genetic correlation of 1.0 (95\% Cl: 0.72-1.00), a complete overlap of additive genetic variance component between HIP and CP, supporting the importance of correlated additive genetic risk factors for the comorbid condition of HIP and CP. HIP was additionally influenced by non-additive genetic factors that did not contribute to the relationship between HIP and CP. There was a significant but moderate child-specific environmental correlation $\left(r_{\mathrm{e}}=0.37\right)$ between HIP and CP. CP was additionally influenced by shared family environmental influences. While the results of the present study are generally consistent with the findings from Western twin studies of the relationship between HIP and CP, they add a new finding to the extant literature by showing that it is additive rather than non-additive genetic factors that are responsible for the co-occurrence of HIP and $C P$.
\end{abstract}

Keywords comorbidity, hyperactivity, inattention, conduct problems, twin, heritability

Conduct disorder (CD) is characterized by behaviors including stealing, lying, truancy from school, and property destruction. Attention deficit/hyperactivity disorder (ADHD) involves pervasive and impairing symptoms of inattention (difficulty concentrating or sustaining attention on a particular task), hyperactivity (fidgetiness, being restless), and impulsivity (acting before thinking, difficulty waiting for turn; American Psychiatric Association, 2004). Epidemiological and clinical samples have shown that ADHD and CD co-occur in 30-50\% of the cases (Angold et al., 1999; Biederman et al., 1991). To understand causal influences on the co-occurrence of ADHD and CD symptoms, several multivariate twin studies have been conducted, which are listed in Table 1.

Silberg et al. (1996) analyzed maternal ratings of hyperactivity and oppositional defiant disorder/conduct disor- der (ODD/CD) symptoms for pre-adolescent and adolescent twins (8-11 years and 12-16 years). Phenotypic correlations between the two problem behaviors ranged from 0.33 to 0.58 across the two age groups. Among preadolescent twins, the covariation between the two problem behaviors was almost entirely explained by common genetic influences; neither shared environmental nor child-specific environmental factors significantly influenced the covariation. As compared to pre-adolescents, however, adoles-

RECEIVED 8 October 2014; ACCEPTED 17 March 2015.

ADDRESS FOR CORRESPONDENCE: Yoon-Mi Hur, Department of Education, Mokpo National University, 61 Dorim-ri, Cheonggye-myeon, Jeonnam, South Korea 534-729. E-mail: ymhur@mokpo.ac.kr 
TABLE 1

A Review of Published Twin Studies of the Relationship Between Hyperactivity/Inattention and Conduct Problems

\begin{tabular}{|c|c|c|c|c|c|c|c|c|}
\hline \multirow[b]{2}{*}{ Author(s) } & \multirow[b]{2}{*}{ Country } & \multirow[b]{2}{*}{$\begin{array}{l}\text { Age of } \\
\text { subjects } \\
\text { (years) }\end{array}$} & \multirow[b]{2}{*}{$N$} & \multirow[b]{2}{*}{$\begin{array}{l}\text { Measure (type } \\
\text { of assessment) }\end{array}$} & \multicolumn{4}{|c|}{ Results } \\
\hline & & & & & $\begin{array}{l}\text { Phenotypic } \\
\text { correlation }\end{array}$ & $\begin{array}{l}\text { Common genetic } \\
\text { influences }\end{array}$ & $\begin{array}{l}\text { Common } \\
\quad \text { shared } \\
\text { environmental } \\
\text { influences }\end{array}$ & $\begin{array}{l}\text { Common } \\
\text { child-specific } \\
\text { environmental } \\
\text { influences }\end{array}$ \\
\hline $\begin{array}{l}\text { Silberg et al. } \\
\quad(1996)\end{array}$ & USA & $\begin{array}{l}\text { 8-11 } \\
\quad \text { (younger) } \\
12-16 \\
\text { (older) }\end{array}$ & 1,197 pairs & $\begin{array}{l}\text { CAPA, Rutter A scale (maternal } \\
\text { rating) }\end{array}$ & $0.33-0.58$ & $\begin{array}{l}\text { Younger: } r_{\mathrm{a}}=1.0 \\
\text { Older: } r_{\mathrm{a}}= \\
0.46-0.58\end{array}$ & ns & $\begin{array}{l}\text { Younger: } r_{\mathrm{e}}= \\
0.07-0.08 \\
\text { Older: } r_{\mathrm{e}}= \\
0.23-0.32\end{array}$ \\
\hline $\begin{array}{l}\text { Nadder et al. } \\
\text { (1998) }\end{array}$ & USA & $7-13$ & 900 pairs & $\begin{array}{l}\text { CAPA (maternal rating; } \\
\text { telephone interview) }\end{array}$ & $0.40-0.53$ & 0.50 & ns & 0.39 \\
\hline $\begin{array}{l}\text { Thapar et al. } \\
\text { (2001) }\end{array}$ & UK & $5-17$ & 2,082 pairs & $\begin{array}{l}\text { DuPaul ADHD rating scale, } \\
\text { ICD-10 symptoms of } \\
\text { hyperkinetic disorder, and } \\
\text { Rutter A scale (all parental } \\
\text { rating, mail survey) }\end{array}$ & NA & $r_{\mathrm{a}}=1.0$ & ns & $r_{\mathrm{e}}=0.39$ \\
\hline Burt et al. (2001) & USA & 11 & 753 pairs & $\begin{array}{l}D S M-I I I-R \text { (face-to-face } \\
\text { interview with parents and } \\
\text { twins) }\end{array}$ & $0.17-0.34$ & ns & $\begin{array}{l}r_{c}=1.0 \\
\quad(0.26-1.0)\end{array}$ & $\begin{aligned} r_{e} & =0.15 \\
& (0.06-0.23)\end{aligned}$ \\
\hline $\begin{array}{l}\text { Nadder et al. } \\
\quad(2002)\end{array}$ & USA & $8-16$ & $\begin{array}{l}494 \text { male \& } \\
603 \\
\text { female } \\
\text { pairs }\end{array}$ & $\begin{array}{l}\text { CAPA (maternal rating, home } \\
\text { visit interview), Rutter B \& } \\
\text { Conners' scale (teacher } \\
\text { rating, mail survey) }\end{array}$ & $0.57-0.64$ & $r_{\mathrm{a}}=0.64-0.82$ & ns & $\begin{array}{l}\text { Mostly } \\
\text { non-significant }\end{array}$ \\
\hline Dick et al. (2005) & Finland & 14 & $>600$ pairs & $\begin{array}{l}\text { C-SSAGA-A (self-report, } \\
\text { face-to-face interview) }\end{array}$ & 0.48 & $r_{a}=0.46(0.13-0.82)$ & ns & $\begin{aligned} & r_{e}=0.18 \\
&(0.01-0.35)\end{aligned}$ \\
\hline $\begin{array}{l}\text { Tuvblad et al. } \\
\text { (2009) }\end{array}$ & USA & $9-10$ & $\begin{array}{l}1,241 \\
\text { individual } \\
\text { twins }\end{array}$ & $\begin{array}{l}\text { DISC-IV (parental rating, } \\
\text { face-to-face interview) }\end{array}$ & 0.37 & $r_{a}=0.43(0.23-0.64)$ & ns & ns \\
\hline $\begin{array}{l}\text { Kerekes et al. } \\
\quad(2014)\end{array}$ & Sweden & $9-12$ & $\begin{array}{l}17,220 \\
\text { individual } \\
\text { twins }\end{array}$ & $\begin{array}{l}\text { A-TAC (parental rating, } \\
\text { telephone interview) }\end{array}$ & $\begin{array}{l}0.44(0.41-0.47) \text { in } \\
\text { boys \& girls }\end{array}$ & $\begin{array}{l}21 \% \text { of covariance in } \\
\text { boys; } 7 \% \text { in girls }\end{array}$ & ns & $\begin{array}{l}\text { Less than } 5 \% \text { of } \\
\text { covariance in } \\
\text { boys and girls }\end{array}$ \\
\hline
\end{tabular}


cents showed somewhat lower genetic correlations ( 0.46 to $0.58)$ and higher child-specific environmental correlations (0.23 to 0.32 ). Shared environmental correlation was not significant in any of the two age groups. Genetic correlation refers to the degree of overlap in genetic factors influencing two phenotypes. Similarly, shared environmental and child-specific environmental correlations represent the degree of overlap in shared family environmental factors and child-specific environmental factors, respectively. As noted in the younger sample of the Silberg et al. study, Thapar et al. (2001) also found genetic correlation of 1.0 between hyperactivity and CP in a large sample of UK twins with a wide age range (5-17 years). Negligible shared environmental correlation and a moderate level of child-specific environmental correlation (0.39) were found in the Thapar et al. study. However, it was not clear whether the magnitudes of genetic and child-specific environmental correlations changed with age as Thapar et al. did not analyze the genetic and environmental relationship separately by age.

Nadder et al. (1998) examined genetic and environmental relationship in a twin sample (7-13 years) using ADHD and ODD/CD symptom data collected from a brief telephone interview. Genetic correlation between the two symptoms was greater than child-specific environmental correlation ( 0.50 vs. 0.39$)$, suggesting that overlapping genetic influences significantly contribute to the covariation of ADHD and ODD/CD, while overlapping child-specific environmental factors exert only moderate influences. In a 19-months follow-up study, Nadder et al. (2002) added teacher ratings and found even higher (0.64 to 0.82$)$ genetic correlations between the two symptoms. It is likely that the genetic correlations were higher in the follow-up because the reliability of teacher rating was higher than that of maternal rating.

Subsequently, two other studies (Dick et al., 2005; Tuvblad et al., 2009) conducted the face-to-face interview in children twin samples with a very narrow age range. Similar to earlier studies, both twin studies found genetic correlations larger than child-specific or shared environmental correlations, confirming the importance of correlated genetic risk for the co-occurrence of ADHD and ODD/CD symptoms. While most twin studies documented a substantial genetic overlap between ADHD and CD, one study found evidence for significant shared environmental overlap with very modest genetic influences. Burt et al. (2001) analyzed symptom counts for ADHD, CD, and ODD obtained from interviews given to 11-year-old twins and their mothers participating in the Minnesota Twin Family Study. The authors reported that a single shared environmental factor made the largest contribution to the covariation among three disorders.

In summary, despite that various twin studies used different samples and types of assessments, except the Burt et al. study (2001), most twin studies of ADHD and CD in children and adolescents supported shared genetic lia- bility as a significant causal risk factor contributing to the comorbidity between CD and ADHD: Genetic correlations typically laid between 0.4 and 1.0, whereas shared environmental and child-specific environmental correlations were negligible or small. One shortcoming common to previous studies is that they did not separate additive versus nonadditive genetic variance, making it difficult to understand how additive genetic and non-additive genetic factors come into play in the etiology of the relationship between ADHD and $\mathrm{CD}$ symptoms. Additive genetic effects represent the sum of the average effect of all alleles that influence a trait, whereas non-additive genetic factors refer to the effects of alleles arising from intra-locus or inter-locus interactions. It has been well documented that in addition to additive genetic effects, non-additive genetic effects exert substantial influences on ADHD symptoms (Nikolas \& Burt, 2010), whereas genetic effects that influence CD are predominantly additive kind (Rhee \& Waldman, 2002). Thus, it is likely that additive genetic effects may be a main source contributing to the relationship between ADHD and CD symptoms. Clarification of the role of additive versus non-additive genetic factors in the covariation of ADHD and CD will have implications in molecular genetic research to identify genes for the comorbid condition of ADHD and CD symptoms. The main goal of the present study was to investigate genetic and environmental etiologies of the covariation of ADHD and CD symptoms in South Korean twin children. By comparing models that included additive genetic and non-additive genetic effects in various ways, it was possible to determine the role of additive and non-additive genetic factors in variations and covariations of ADHD and CD symptoms.

\section{Methods}

\section{Sample}

Subjects in the present study were 507 complete pairs of twins drawn from the South Korean Twin Registry (SKTR; Hur et al., 2013). The sample consisted of $221 \mathrm{MZ}$ and 286 DZ twin pairs. DZ twins included 144 pairs of oppositesex twins. Twins ranged in age from 6 to 13 years (Mean $=9.6$ years; $S D=2.0$ years), which roughly covered the elementary school period in South Korea. The total sample included $44.5 \%$ of female twins. To maximize statistical power of the sample, male and female twins were combined prior to twin analysis.

Zygosity was determined from mothers' responses to questions about physical similarity of the twins and frequency of confusion by others (Ooki et al., 1993). As the questionnaire method is less accurate than DNA analysis to determine twins' zygosity; however, we excluded twins whose zygosity was ambiguous from data analyses.

\section{Measures}

As part of the SKTR's telephone survey, a Korean version of the SDQ (Ahn et al., 2003) was given to mothers of twins. 
In order to reduce the tendency for mothers to give similar ratings or contrast twins, mothers were asked to respond to all items in the telephone battery regarding the first-born twin, and then all items regarding the second-born twin. The SDQ is one of the most commonly used instruments for screening psychopathology in children and adolescents worldwide; it consists of five scales (Emotional Problems, Peer Problems, HIP, CP, and Prosocial Behavior). Although each of these scales have only five items, the scales have been shown to be valid in identifying psychopathology in the community as well as in the clinical samples (Goodman et al., 2000a; 2000b). After a review of 48 studies based on the SDQ scales, Stone et al. (2010) concluded that internal consistency, test-retest reliability, and validity of the scales were satisfactory across different age groups and sexes. The HIP and CP scales were used for the present study. The five items of the $\mathrm{CP}$ scale are: 'Often loses temper', 'Generally well behaved, and obedient to adults', 'Often fights with other children or bullies them', 'Often lies or cheats', and 'Steals from home, school or elsewhere'. The five items of the HIP scale are: 'Restless, overactive, cannot stay still for long,' 'Constantly fidgeting or squirming, 'Easily distracted, concentration wanders', 'Thinks things out before acting', and 'See work through to the end, good attention span'. Mothers of twins were instructed to rate their twin children's behaviors on a three-point Likert scale ranging from not true (0) to certainly true (2). Internal consistency reliabilities were 0.76 for the HIP scale and 0.51 for the $\mathrm{CP}$ scale in the present sample.

\section{Statistical Analyses}

To investigate shared genetic and environmental etiologies of the relationship between CP and HIP, twin correlations and cross-twin cross-trait correlations (e.g., twin 1's CP with twin 2's HIP) for MZ and DZ twins were computed, and bivariate model-fitting analyses were carried out. Age and sex were treated as covariates in correlational and modelfitting analysis.

Model-fitting analysis was conducted on the basis of the bivariate Cholesky decomposition model that includes additive genetic factor (A), non-additive genetic factors (D), shared environmental factors ( $\mathrm{C}$; the effects of environment shared by two members of a twin pair), and child-specific environmental factors confounded with measurement error (E; the effects of environment specific to each member of a twin pair). The bivariate Cholesky model allows us to evaluate the extent to which common genetic and environmental influences contribute to the covariation between the two phenotypes. Thus, the full bivariate Cholesky model in the present study specifies additive genetic factors for HIP that also influence $\mathrm{CP}$ (pathways a11 and a21) and additive genetic factors unique to $\mathrm{CP}$ (a22). Similarly, non-additive genetic factors (d11, d21, and d22), shared environmental factors (c11, c21, and c22), and child-specific environmental factors (e11, e21, and e22) are each specified by two latent variables, following the same pattern as those specifying additive genetic factors. Standardizing the additive and non-additive genetic and shared environmental and child-specific environmental covariance matrices provide the respective correlation matrices across HIP and CP.

The maximum likelihood raw data option in $\mathrm{Mx}$ (Neale et al., 2003) was used to carry out model-fitting analyses. Mx calculates twice the negative log-likelihood (-2LL) of the data. As the difference in -2LL is distributed as chi-square, when models were nested to each other, the likelihood ratio test (LRT) was used to compare full models to reduced models where one or more parameters were removed. A significant increase in chi-square in the reduced model as compared to the full model would suggest that the reduced model fit the data less well than the full model. On the other hand, a non-significant change in chi-square in the reduced model would indicate that the reduction of the model parameter is acceptable, and thus the reduced model is preferred over the full model. When models were not nested to each other, Akaike's information criterion (AIC $=-2 \mathrm{LL}-2 d f$ ) for alternative models were compared. Models having lower AIC were considered more parsimonious, and thus preferred (Akaike, 1987).

For a baseline comparison, a saturated model was created. Means, variances, and covariances were allowed to vary across zygosity groups in the saturated model. First, three full models, that is, the ACE bivariate model for HIP and $\mathrm{CP}$, the ADE bivariate model for HIP and $\mathrm{CP}$, and the $\mathrm{ADE}$ model for HIP and the ACE model for $\mathrm{CP}$ were constructed and -2LL of these three full models were compared with that of the saturated model. Next, parameters were removed from the full model and the changes in -2LL were examined to determine the best fitting, most parsimonious model to explain the relationship between HIP and CP.

\section{Results}

\section{Descriptive Statistics and Twin Correlations}

Means and standard deviations for HIP and CP for MZ and $\mathrm{DZ}$ twins are presented in Table 2. Age was not significantly correlated with HIP $(r=-0.01)$ in the present sample. The correlation between age and $\mathrm{CP}$ was very modest but significant $(r=-0.09, p<.01)$. Males had significantly higher mean and variance than females for HIP $(t=9.1, p<.01 ; F$ $=49.8, p<.01)$ and $\mathrm{CP}(t=2.2, p<.05 ; F=5.5, p<.05)$. Twins were not significantly different across zygosity groups in the mean levels or variances of HIP and CP, indicating absence of zygosity effects. No significant mean or variance differences were found between the first- and the secondborn twins, suggesting no significant birth-order effects on HIP and CP.

Maximum likelihood MZ and DZ twin correlations for HIP were, respectively, 0.48 (95\% CI: 0.37-0.58) and 0.06 (95\% CI: $-0.06-0.19)$, confirming genetic influences found in the previous study on the basis of the 
TABLE 2

Sample Size, Mean (SD) Age, and Maximum Likelihood Monozygotic (MZ) and Dizygotic (DZ) Twin Correlations and Their $95 \% \mathrm{Cl}$ and Mean (SD) for Hyperactivity/Inattention and Conduct Problems

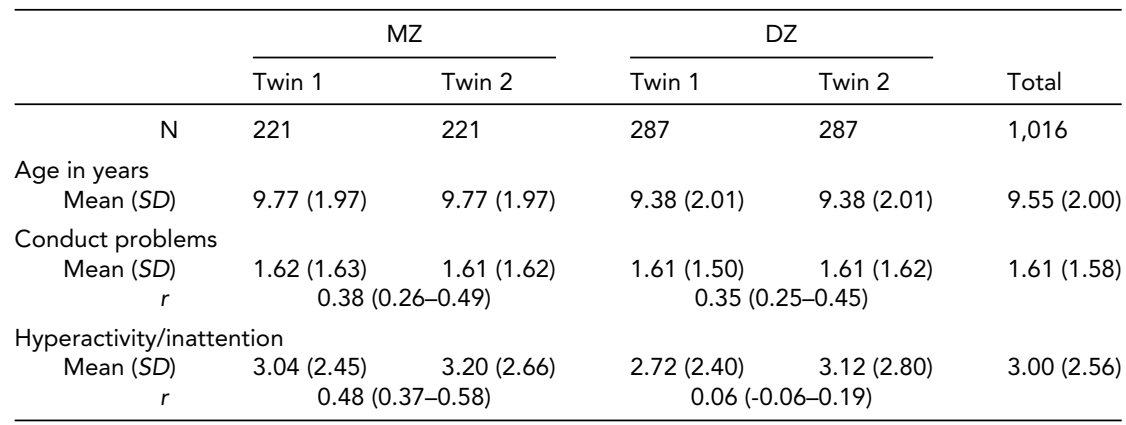

TABLE 3

Results of Bivariate Model-Fitting Analysis

\begin{tabular}{lllllll}
\hline & & \multicolumn{5}{c}{ Test statistics } \\
\cline { 3 - 7 } Model & Description & $-2 \mathrm{LL}$ & $d f$ & AIC & $\Delta d f$ & $\Delta \chi^{2}$ \\
\hline 1 & Saturated & $5,399.7$ & 2,000 & $1,399.7$ & & \\
2 & ACE for HIP \& CP & $5,430.4$ & 2,017 & $1,396.4$ & 17 & $30.7^{*}$ \\
3 & ADE for HIP \& CP & $5,431.8$ & 2,017 & $1,397.8$ & 17 & $32.1^{*}$ \\
$\mathbf{4}$ & ADE for HIP \& ACE for CP & $\mathbf{5 , 4 2 6 . 9}$ & $\mathbf{2 , 0 1 8}$ & $\mathbf{1 , 3 9 0 . 9}$ & 18 & $\mathbf{2 7 . 2}$ \\
5 & Drop D for HIP & $5,431.8$ & 2,019 & $1,393.8$ & 19 & $32.1^{*}$ \\
6 & Drop C for CP & $5,433.2$ & 2,019 & $1,395.2$ & 19 & $33.5^{*}$ \\
7 & Drop $r_{\mathrm{a}}$ & $5,451.2$ & 2,019 & $1,413.2$ & 19 & $51.5^{* *}$ \\
8 & Drop $r_{\mathrm{e}}$ & $5,474.9$ & 2,019 & $1,436.9$ & 19 & $75.2^{* *}$ \\
\hline \multirow{2}{*}{ Note: ${ }^{*} p$} & $<.05, * * p<.01$. The best-fitting model is indicated in boldface. & &
\end{tabular}

subsample in the present study (Hur, 2014). Especially, DZ twin correlation less than half of $\mathrm{MZ}$ twin correlation suggested the presence of non-additive genetic factors for HIP. Maximum likelihood MZ and DZ twin correlations for CP were, respectively, 0.38 (95\% CI: 0.26-0.49) and 0.35 (95\%CI: $0.25-0.45$ ), which indicated the importance of shared environmental influences. Overall, these twin correlations suggested that the full model should include ADE for HIP and ACE for CP.

The phenotypic correlation between HIP and CP was $0.43(p<.01)$, indicating a significant relationship between the two problem behaviors. Cross-twin cross-trait correlations were 0.20 for $\mathrm{MZ}$ and 0.07 for $\mathrm{DZ}$ twins. Higher MZ than DZ cross-twin cross-trait correlation suggested genetic influences on the relationship between HIP and CP. However, MZ cross-twin cross-trait correlation was much less than the phenotypic correlation, which indicated the presence of child-specific environmental factors on the relationship between HIP and CP.

\section{Model-Fitting Analyses}

The results of bivariate model-fitting analyses are summarized in Table 3. Models 2 and 3 (the ACE full model and the ADE full model) yielded a significantly larger -2LL as compared to that of the saturated model. However, a non- significant difference in -2LL was observed in model 4 (the ADE model for HIP and the ACE model for CP), which was consistent with expectations from $\mathrm{MZ}$ and $\mathrm{DZ}$ twin correlations for HIP and CP (Table 1). Parameters were further removed from model 4 , but all of the reduced models tested produced a significant difference in -2LL (see models 5 to 8). A significant decrease in model fit was especially notable in models 7 and 8 where additive genetic correlation $\left(r_{\mathrm{a}}\right)$ and child-specific environmental correlation $\left(r_{\mathrm{e}}\right)$ were individually eliminated from model 4. Among all models tested, model 4 had the lowest AIC value. Thus, model 4 was chosen as the best-fitting, most parsimonious model to explain the data.

Figure 1 presents path coefficients in the best-fitting model that included a single additive genetic factor that influences HIP and CP together $\left(\mathrm{A} ; r_{\mathrm{a}}=1.0\right)$, non-additive genetic factors specific to HIP (D), shared environmental factors unique to $\mathrm{CP}(\mathrm{C})$, and child-specific environmental variances and covariance in HIP and $\mathrm{CP}$ (E1 and E2; $r_{\mathrm{e}}=$ 0.37). Additive genetic correlation of 1.0 (95\% CI: $0.72-$ 1.0) in the model indicated a complete overlap of additive genetic variance between HIP and CP. However, it should be noted that there were additional genetic influences on HIP that operate in non-additive manner. Child-specific environmental correlation of 0.37 (95\%CI: 0.27-0.46) sug- 


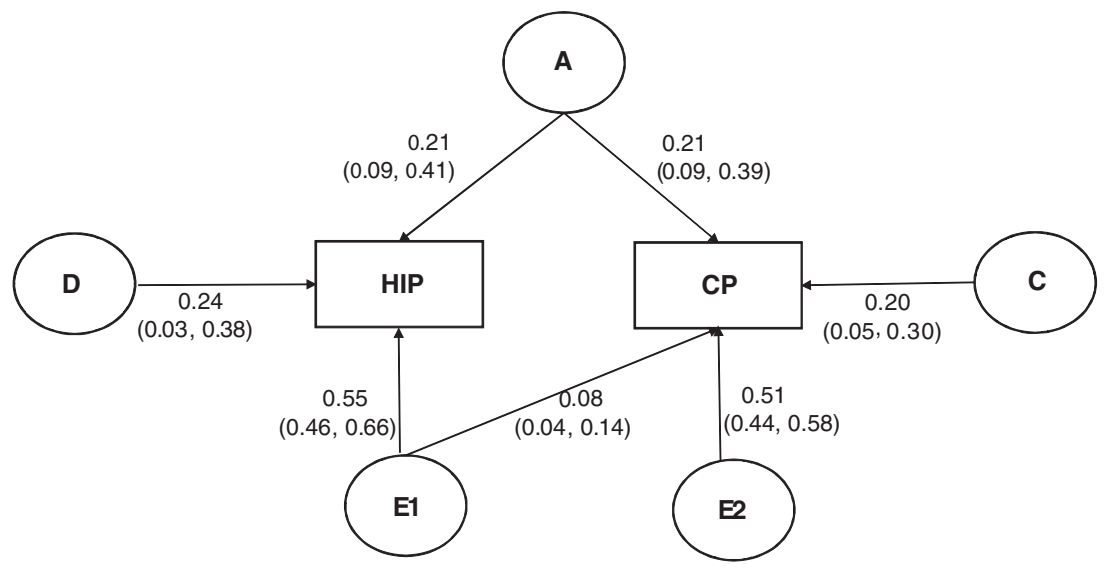

\section{FIGURE 1}

Variance components (i.e., squared standardized parameter estimates) in the best-fitting bivariate model for the relationship between HIP (Hyperactivity/inattention problems) and CP (Conduct problem); $95 \% \mathrm{Cl}$ are in parenthesis. $\mathrm{A}=$ additive genetic influences, $\mathrm{D}=$ non-additive genetic influences, $C=$ shared environmental influences, $E=$ child-specific environmental influences and measurement error.

gested a moderate overlap of child-specific environmental factors that influence HIP and CP. Note, however, that CP was significantly influenced by shared environmental factors as well. There also existed a substantial amount of child-specific environmental factors unique to CP and HIP, suggesting that environmental influences on HIP and CP may be quite independent.

In the best fitting model, additive genetic, non-additive genetic, and child-specific environmental variance components were, respectively, 0.21 (95\% CI: 0.09-0.41), 0.24 (95\%CI: $0.03-0.38$ ), and 0.55 (95\% CI: 0.46-0.66) for HIP, and additive genetic, shared environmental, and childspecific environmental variance components were, respectively, 0.21 (95\% CI: 0.09-0.39), 0.20 (95\%CI: 0.05-0.30), and 0.59 (95\%CI: 0.51-0.68) for CP. These parameter estimates in the best fitting model revealed that approximately $51 \%(r=0.22 ; \sqrt{ } .21 \times \sqrt{ } .21)$ of the phenotypic correlation of 0.43 between HIP and CP were due to correlated additive genetic factors, and the remaining $49 \%(r=0.21$; $0.37 \times \sqrt{ } .55 \times \sqrt{ } .59)$ were attributable to correlated childspecific environmental factors. Neither non-additive genetic factors, nor shared environmental factors, contributed to the phenotypic relationship between HIP and CP.

\section{Discussion}

Over the past two decades, there has been increased research into the genetic etiology of the co-occurrence of HIP and CP. The present study provided a new finding to the extant literature by demonstrating that it is additive rather than non-additive genetic variance component that causes comorbidity between HIP and CP in children. As prior twin studies of the relationship between HIP and CP did not separate additive versus non-additive genetic factors, the nature of the genetic relationship remained unclear. How- ever, the present study showed that non-additive genetic factors only influenced HIP and did not contribute to the comorbidity between the two problem behaviors. Most of the environmental factors that increased the risk for HIP did not exert influences on $\mathrm{CP}$ and vice versa, as $\mathrm{CP}$ was significantly determined by shared environmental influences, whereas HIP was largely influenced by child-specific environmental factors. In agreement with the previous studies, however, the present study also showed a moderate correlation of child-specific environmental factors between HIP and CP. Given that child-specific environmental factors include measurement error, the correlation of child-specific environmental factors found in the present study may partly contain correlated measurement error arising from the use of two scales derived from the same instrument (SDQ). Furthermore, it should be noted that the internal consistency reliability of the CP scale was lower than that of the HIP scale in the present sample. As measurement error is confounded with the estimate of child-specific environmental influences in model-fitting analysis, child-specific environmental influence on CP found in the current sample may be biased toward an upper estimate.

The phenotypic correlation of 0.43 between HIP and CP found in the present sample was generally within the range that the majority of Western twin studies have showed (see Table 1). Also, the additive genetic correlation of 1.0 and child-specific environmental correlation of 0.37 were remarkably similar to the results reported by Thapar et al. (2001), although the Thapar et al. study was on the basis of a sample much larger than the current sample and used a categorical approach based on different rating scales. Overall, the results revealed from the present South Korean twin sample were very close to the findings from the previous Western twin studies of the relationship between ADHD and CD symptoms, shown in Table 1 . Thus, the present 
results extend the Western findings of genetic and environmental etiologies of the comorbidity between ADHD and $\mathrm{CD}$ to Asians, contributing to the cross-cultural generality of this research topic.

To date, several molecular genetic studies have been successful in detecting genes for ADHD and CD (Faraone \& Mick, 2010). The substantial amount of additive genetic correlation found in the current sample suggests that genes that influence HIP also increase CP in children, and therefore specific genes involved in HIP should be investigated as potential risk genes for $\mathrm{CP}$ and vice versa. Additionally, as the present study suggests that genes that act additively are primary sources that cause the comorbid condition of $\mathrm{ADHD}$ and $\mathrm{CD}$, inclusion of parents in the molecular genetic samples may be more effective in identifying genes for the comorbid condition of ADHD and CD.

The presence of child-specific environmental correlation between HIP and CP found in the present study is consistent with the evidence in the literature that CD and ADHD symptoms are both linked with peer rejection (Mrug et al., 2012; Murray-Close et al., 2010) and a high level of conflicts with parents (Burt et al., 2003; Ebejer et al., 2012), although some of these negative life experiences may arise as a result of the child's symptoms. The finding of significant childspecific environmental correlation between HIP and CP is important as it implies that the environmental intervention method effective for one disorder can be a potential treatment option for the other disorder.

There are several limitations in the present study that need to be addressed. First, the present sample covered only 6- to 13-year-old twins. Given the complex developmental trajectory of ADHD symptoms (Ebejer et al., 2012; Robbers et al., 2011), the pattern of the comorbidity between HIP and CP may change throughout development. Ideally, the changing pattern of genetic and environmental etiologies of the comorbidity between ADHD and CD symptoms should be studied through longitudinal twin studies. Second, only mothers were used to assess twins' behavior problems in the present study. It has been well documented that parents tend to either exaggerate similarities or differences in their twin children (e.g., Saudino et al., 2000). If this bias occurs, variance differences between $\mathrm{MZ}$ and $\mathrm{DZ}$ twins in combination with a very low or negative DZ twins are expected. However, the patterns of MZ and DZ twin correlations and variances in HIP and CP suggest that the effects of rater bias may not be serious in the present data (see Table 2). Third, the HIP and CP scales of the SDQ are both short, and therefore may not fully contain symptoms of $\mathrm{ADHD}$ and CD. In the future, the present findings should be replicated, employing longer and more extensively validated measures of ADHD and CD. Finally, as a large sample is necessary to separately estimate non-additive versus additive genetic effects (Martin et al., 1978), additional research with a larger sample size is clearly needed to replicate present findings.

\section{Acknowledgments}

This study was supported by the National Research Foundation of Korea (NRF-371-2011-1 B00047). I would like to thank twins and their parents who participated in this study.

\section{References}

Ahn, J.-S., Jun, S.-K., Han, J.-K., Noh, K.-S., \& Goodman, R. (2003). The development of a Korean version of the strengths and difficulties questionnaire. Journal of Korean Neuropsychiatric Association, 42, 141-147.

Akaike, H. (1987). Factor analysis and AIC. Psychometrika, 52, 317-332.

American Psychiatric Association. (2004). Diagnostic and statistical manual of mental disorders. Washington, DC: Author

Angold, A., Costello, J. E., \& Erkanli, A. (1999). Comorbidity. Journal of Child Psychology and Psychiatry, 40, 57-87.

Biederman, J., Newcorn, J., \& Sprich, S. (1991). Comorbidity of attention deficit hyperactivity disorder with conduct, depressive, anxiety, and other disorders. American Journal of Psychiatry, 148, 564-577.

Burt, S. A., Krueger, R. F., McGue, M., \& lacono, W. G. (2001). Sources of covariation among attentiondeficit/hyperactivity disorder, oppositional defiant disorder, and conduct disorder: The importance of shared environment. Journal of Abnormal Psychology, 110, 516-525.

Burt, S. A., Krueger, R. F., McGue, M., \& Iacono, W. (2003). Parent-child conflict and the comorbidity among childhood externalizing disorders. Archives of General Psychiatry, 60, 505-513.

Dick, D. M., Viken,, R. J., Kaprio,, J., Pulkkinen, L., \& Rose, R. J. (2005). Understanding the covariation among childhood externalizing symptoms: Genetic and environmental influences on conduct disorder, attention deficit hyperactivity disorder, and oppositional defiant disorder symptoms. Journal of Abnormal Child Psychology, 33, 219-229.

Ebejer, J. L., Medland, S. E., van der Werf, J., Gondro, C., Henders, A. K., Lynskey, M., \&mldr; Martin, N. G. (2012). Attention deficit hyperactivity disorder in Australian adults: Prevalence, persistence, conduct problems and disadvantage. PLOS One, 7, e47404.

Faraone, S. V. \& Mick, E. (2010). Molecular genetics of attention deficit hyperactivity disorder. The Psychiatric Clinics of North America, 33, 159-180.

Goodman, R., Ford, T., Simmons, H., Gatward, R., \& Meltzer, H. (2000a). Using the strengths and difficulties questionnaire (SDQ) to screen for child psychiatric disorders in a community sample. British Journal of Psychiatry, 177, 534539.

Goodman, R., Renfrew, D., \& Mullick, M. (2000b). Predicting type of psychiatric disorder from strengths and difficulties questionnaire (SDQ) scores in child mental health clinics in London and Dhaka. European Child and Adolescent Psychiatry, 9, 129-134.

Hur, Y.-M. (2014). Increasing phenotypic and genetic variations in hyperactivity/inattention problems from age 3 to 
13 years: A cross-sectional twin study. Twin Research and Human Genetics, 17, 545-552.

Hur, Y.-M., Jeong, H.-U., Chung, K. W., Shin, J. S., \& Song, T.-B. (2013). The South Korean Twin Registry: An update. Twin Research and Human Genetics, 16, 237-240.

Kerekes, N., Lundström, S., Chang, Z., Tajnia, A., Jern, P., Lichtenstein, P., \&mldr; Nilsson, T. (2014). Oppositional defiant- and conduct disorder-like problems: Neurodevelopmental predictors and genetic background in boys and girls, in a nationwide twin study. Peer J, 22, e359.

Martin, N. G., Eaves, L. J., Kearsey, M. J., \& Davies, P. (1978). The power of the classical twin study. Heredity, 40, 97-116.

Mrug, S., Molina, B. S., Hoza, B., Gerdes, A. C., Hinshaw, S. P., Hechtman, L., \& Arnold, L. E. (2012). Peer rejection and friendships in children with attention-deficit/hyperactivity disorder: Contributions to long-term outcomes. Journal of Abnormal Child Psychology, 40, 1013-1026.

Murray-Close, D., Hoza, B., Hinshaw, S. P., Arnold, L. E., Swanson, J., Jensen, P. S., \&mldr; Hechtman, L. (2010). Developmental processes in peer problems of children with attention-deficit/hyperactivity disorder in the multimodal treatment study of children with ADHD: Developmental cascades and vicious cycles. Development and Psychopathology, 22, 785-802.

Nadder, T. S., Rutter, M., Silberg, J. L., Maes, H. H., \& Eaves, L. J. (2002). Genetic effects on the variation and covariation of attention deficit-hyperactivity disorder (ADHD) and oppositional-defiant disorder/conduct disorder (ODD/CD) symptomatologies across informant and occasion of measurement. Psychological Medicine, 32, 3953.

Nadder, T. S., Silberg, J. L., Eaves, L. J., Maes, H. H., \& Meyer, J. M. (1998). Genetic effects on ADHD symptomatology in 7- to-13-year-old twins: Results from a telephone survey. Behavior Genetics, 28, 83-99.

Neale, M. C., Boker, S. M., Xie, G., \& Maes, H. H. (2003). Mx: Statistical modeling (5th ed.). Richmond, VA: Department of Psychiatry, Virginia Commonwealth University.
Nikolas, M. A., \& Burt, S. A. (2010). Genetic and environmental influences on ADHD symptom dimensions of inattention and hyperactivity: A meta-analysis. Journal of Abnormal Psychology, 119, 1-17.

Ooki, S., Yamada, K., \& Asaka, A. (1993). Zygosity diagnosis of twins by questionnaire for twins' mothers. Acta Geneticae Medicae et Gemellologiae, 42, 17-22.

Rhee, S. H., \& Waldman, I. D. (2002). Genetic and environmental influences on antisocial behavior: A meta-analysis of twin and adoption studies. Psychological Bulletin, 128, 490-529.

Robbers, S. C. C., van Oort, F. V. A., Polderman, T. J. C., Bartels, M., Boomsma, D. I., Verhulst, F. C., \&mldr; Lubke, G. H. (2011). Trajectories of CBCL attention problems in childhood. European Child \& Adolescent Psychiatry, 20, 419-427.

Saudino, K. J., Cherny, S. S., \& Plomin, R. (2000). Parent ratings of temperament in twins: Explaining the 'too low' DZ correlations. Twin Research, 3, 224-233.

Silberg, J., Rutter, M., Meyer, J., Maes, H., Hewitt, J., Simonoff, E., \&mldr; Pickles, A. (1996). Genetic and environmental influences on the covariation between hyperactivity and conduct disturbance in juvenile twins. Journal of Child Psychology and Psychiatry, 37, 803-816.

Stone, L. L., Otten, R., Engels, C. M. E., Vermulst, Ad. A., \& Janssens, M. A. M. (2010). Psychometric properties of the parent and teacher versions of the strengths and difficulties questionnaire for 4- to 12-year-olds: A review. Clinical Child and Family Psychology Review, 13, 254-274.

Thapar, A., Harrington, R., \& McGuffin, P. (2001). Examining the comorbidity of ADHD-related behaviours and conduct problems using a twin study design. The British Journal of Psychiatry, 179, 224-229.

Tuvblad, C., Zheng, M., Raine, A., \& Baker, L. A. (2009). A common genetic factor explains the covariation among ADHD, ODD and CD symptoms in 9-10 year old boys and girls. Journal of Abnormal Child Psychology, 37, 153167. 